Revista Internacional de Sociología (RIS)

Vol.68, № 2, MaYo-Agosto, 429-452, 2010

ISSN: 0034-9712

eISSN: 1988-429X

DOI:10.3989/ris.2008.08.13

\title{
EL ESPEJISMO DE UNA ENERGÍA SOCIAL La economía del hidrógeno
}

\author{
THE MIRAGE SOCIAL ENERGY \\ The Economy of the Hydrogen
}

Jesús A. Valero Matas

Universidad de Valladolid. España

valeroma@soc.uva.es

\section{Resumen}

El texto reflexiona sobre la economía del hidrógeno. Una esperanza que abrió Rifkin en su obra La economía del hidrógeno (2002) como solución a los carburantes fósiles y al efecto invernadero. Este nuevo "dorado" energético que iba a solucionar los problemas energéticos de la humanidad, en especial a los más desfavorecidos, no ha llegado, y posiblemente nunca llegue en los términos de Rifkin. Las cuestiones que impiden desarrollar la economía del hidrógeno son múltiples, entre ellas sus impactos sociales. La divulgación de las tesis de Rifkin abrieron la esperanza a muchos sectores de la sociedad, y tras el paso de los años esto no se ha cumplido y está lejos de hacerse realidad. Se exponen algunas razones por las cuales la economía "social" del hidrógeno no podrá convertirse en esa energía de salvación social.

\section{Palabras Clave}

Ciencia, Tecnología y sociedad, Cambio social, Combustible, Impacto social, Energía renovable.

\section{Abstract}

This paper is a critical examination of proposals for a "hydrogen economy." In Jeremy Rifkin's The Hydrogen Economy (2002) such an economy was proposed as a solution to the many problems associated with the use of fossil fuels including the dangers of global climate change. The promise has been echoed since by many others who have been concerned by energy policy. Hydrogen has increasingly been viewed as a "dorado" energy that would greatly benefit all humanity, especially the most disadvantaged. But the golden age of energy has not yet appeared and may never do so. There are multiple problems in the development of a hydrogen economy. One of these problems concerns social impacts, which have especially been ignored. It is the potential social impacts of a hydrogen economy that are given special attention here, in order to explore some of the reasons for doubting that the social economy of hydrogen will be able to realize the many hopes associated with it.

\section{KEYWORDS}

Fuel, Renewable energy, Social Impact, Science, Technology and Society, Social Change. 


\section{INTRODUCCIÓN ${ }^{1}$}

Desde hace décadas se viene investigando sobre diferentes alternativas energéticas con el objeto de reducir o suplir la dependencia de los combustibles fósiles, así como frenar o erradicar la emisión de gases con efecto invernadero. Esto que en cierto modo preocupa a las políticas nacionales e internacionales ha conllevado en el último lustro una mayor incidencia en los programas gubernamentales, con el objeto de ir perfilando medidas de contención en la emisión de gases de efecto invernadero y reducir la dependencia de los combustibles fósiles. Quizá el mayor alegato surgió en 2003 cuando G. W. Bush dijo que había que investigar sobre el hidrógeno como fuente de energía a modo de solución al problema del petróleo y derivados. Esta apuesta tuvo su referente en la obra del Rifkin (2002) The Hydrogen Economy, la cual ha sido un canto a la solución de los problemas energéticos del planeta. Siguiendo esta estela, Bush emprendió la andadura en busca del santo grial energético, y posteriormente la UE hizo lo propio. Ambos han destinado ingentes cantidades de dinero y capital humano en desarrollar el hidrógeno como la fuente energética del futuro.

El 17 de Julio de 2008 (The Washington Post) el ex candidato a la Casa Blanca y reconvertido activista verde Al Gore, en una conferencia en Washington reclamaba al Gobierno, que en los próximos 10 años desaparecieran todos los productos energéticos con emisiones de carbono, y se diera paso a la era energética libre.

Todo esto acontece cuando países como Rusia o Alemania por esas mismas fechas emprendieron viajes por los países del Magreb buscando una alianza energética en torno al gas natural y el petróleo. La multinacional rusa Gazprom pidió a Libia comprar toda su producción de gas líquido (GLN). Mientras unos abogan por una erradicación total -como ha empezado a hacer Islandia - de los derivados del petróleo, otros como Alemania y Rusia persiguen situarse estratégicamente en torno a los combustibles fósiles.

Se percibe cierto interés por las energías renovables como fuente energética alternativa, pero más como imagen institucional que por implicación real. En este juego lo que probablemente subyace es que existe una cuestión sobremanera importante, y no es otra que la inexistencia de una fuente energética limpia capaz de sustituir al petróleo. A nuestro juicio esto es lo que acontece, y por eso, los gobiernos mantienen silencio y van parcheando la situación del cambio climático y emisiones de $\mathrm{CO}_{2}$ con propuestas de baja influencia y alto coste.

\footnotetext{
${ }^{1}$ Este artículo ha sido escrito gacias a la ayuda concedida por la Consejería de Educación de la Junta de Castilla y León, para movilidad de profesores, en Colorado School of Mines, y al amparo del proyecto de investigación "Infraestructuras-investigación termodinámica de combustibles innovadores renovables procedentes de la biomasa y del hidrógeno para su uso en automoción (GR152) dirigido por el catedrático de Física Miguel A. Villamañan. También quiero agradecer a Carl Mitcham su apoyo y los comentarios del artículo.
} 
El agotamiento del petróleo en las próximas décadas parece un hecho, por la cantidad de multinacionales del sector que andan realizando prospecciones en cualquier lugar de la tierra, y están apostando por energías renovables. La importancia adquirida por el gas natural y su intensidad en la economía mundial, se le estima una duración no muy superior a la del petróleo. Su consumo comporta seguir con las alteraciones del cambio climático por la quema de hidrocarburos fósiles emisores de bióxido de carbono. En estos momentos, la etiquetada psicosis verde ha levantado mucho interés de científicos, ingenieros, industria y políticos en fomentar el hidrógeno como combustible y portador de energía en el futuro. Se avizora que el hidrógeno en un futuro, especialmente, en el sector del transporte, jugará un papel importante. Prácticamente dos maneras pueden hacer que un vehículo funcione con hidrógeno: mediante un motor de combustión interna o utilizando una pila de combustible.

La economía del hidrógeno posibilita una enorme redistribución del poder, con consecuencias trascendentales para la sociedad. Como es el potencial sobre el papel del hidrógeno para poner fin a la hegemonía y dependencia del petróleo y la erradicación del contubernio y peligroso juego geopolítico mantenido entre los países musulmanes productores de petróleo y los países occidentales. Pero también, reducirá las emisiones de dióxido de carbono y mitigará los efectos del calentamiento global.

La abundancia de hidrógeno en el planeta y su poder energético son innegables, pero la cuestión no está en hablar de los potenciales beneficios del hidrógeno, sino en resolver la cuestión energética: ¿Podrá el hidrógeno ser la energía del futuro como pretenden hacernos creer? Sobre esta cuestión intentamos arrojar luz en las siguientes páginas.

\section{EL HIDRÓGENO COMO TRANSMISOR DE ENERGÍA}

Desde hace siglos el ser humano ha manejado diferentes fuentes de energía para cubrir sus necesidades, primero la madera, luego el carbón, el petróleo, la energía nuclear, las energías renovables, y ahora busca en el hidrógeno el nuevo dorado energético. Gracias a la investigación de la ciencia y la tecnología, el ser humano ha ido mejorando su calidad de vida gracias a la aportación de nuevos instrumentos a lo cotidiano, calefacción, vitreocerámicas, automóviles, las telecomunicaciones, las videoconsolas, etc., y todo en su justa medida ha generado mudanza social. La energía no sólo repercute sobre los bienes de consumo, también incide directamente sobre la producción de bienes básicos, los vegetales, las legumbres o los huevos entre otros.

Desde hace un siglo, el petróleo viene siendo nuestra principal fuente de energía. Unos años atrás, diferentes voces comenzaron a reclamar alternativas energéticas, por el posible agotamiento del petróleo y los efectos negativos de los hidrocarburos sobre el medio ambiente. El descenso de las bolsas de petróleo está llevando a las grandes petroleras denodadamente a rastrear nuevas reservas de petróleo. Tal es la situación 
que las petroleras se han embarcado en explorar en la Antártida y el Ártico, consideradas reservas sólo con proyecciones científicas. Ante posibles hallazgos, los países limítrofes se están repartiendo el territorio.

Ante esta realidad surgen diferentes posiciones geoestratégicas para hacer frente al petróleo investigando y desarrollando nuevas fuentes de energía. Con esta situación de fondo y enarbolando el estandarte del efecto invernadero se planteó la economía del hidrógeno como posible agente energético en sustitución de los carburantes fósiles. Sus características le situaban en una situación privilegiada para competir y desbancar a los combustibles fósiles, vendiéndolo como energía limpia, económica y saludable.

Se atribuye el descubrimiento del hidrógeno al científico británico Cavendish, quien en 1766 observó que era diferente a otros gases inflamables. Pero sería el francés Lavoisier el responsable de su nombre, "hidrógeno: productor de agua". Ya en el siglo $\mathrm{XVI}$ los alquimistas sabían que cuando el aceite de vitriolo (ácido sulfúrico) actuaba sobre limaduras de hierro se desprendía un gas combustible, pero desconocían su naturaleza. Paracelso fue el primero en describir el hidrógeno como gas, al mezclar metales con ácidos fuertes. Más tarde, en 1671, Boyle describiría cómo la reacción producida entre limaduras de hierro y ácidos diluidos generaba hidrógeno gaseoso. El hidrógeno se licuó por primera vez en 1898 y el científico responsable fue Dewar.

El hidrógeno es el elemento químico más abundante en el universo, y en condiciones normales se encuentra en estado gaseoso. Es el más común y ubicuo de los elementos químicos. El hidrógeno es, energéticamente hablando, inagotable. A pesar de ser el más abundante no se encuentra en estado puro, sino que está presente en forma molecular 0 iónica. Como apunta Gutiérrez Jodra (2005: 50) el posible yacimiento más próximo está en Júpiter, inaccesible por el momento.

Por lo tanto, el hidrógeno no es una fuente primaria de energía, sino un vector, y en consecuencia para obtenerlo se necesita la descomposición química del elemento al que se encuentra asociado. La forma más habitual de encontrar el hidrógeno es el agua, para obtenerlo se debe separar del oxígeno suministrando una corriente eléctrica (electrolisis) generada por una fuente de energía primaria. Para que su obtención sea rentable se recurre a fuentes de energía renovables (eólica, solar, geotérmica, etc.).

Sobre la consideración del hidrógeno como vector energético conviene destacar una serie de características: 1) bajos puntos de ebullición y proximidad a la temperatura crítica; 2) bajas densidades del gas y del líquido; 3) su contenido en deuterio, que puede ser una de las bases de la energía nuclear de fusión (Gutiérrez Jodra 2005: 50-51).

La economía del hidrógeno como red está compuesta por tres etapas funcionales, producción, almacenamiento y uso, y existen medios técnicos para lograr estas tres cosas, pero ahora mismo no es posible, incluso, el método más barato para obtener hidrógeno, por medio del reformado catalítico de gas natural con vapor, es más costoso que la gasolina (Ogden 2002: 69). Si además adicionamos el coste del resto de etapas, el precio de consumo se dispara.

Las características más atractivas hacia el hidrógeno como transmisor de energía residen en su limpieza. Por la ausencia de carbono en el proceso de transición a la gene- 
ración de energía que no se producen emisiones de $\mathrm{CO}_{2}$. En segundo lugar su potencial energético.

Su limpieza y potencialidad energética abrió grandes expectativas a los defensores del cambio climático, y algunas empresas de automóviles divisaron una nueva forma de motorización con carburantes de hidrógeno. Ciencia y tecnología llevan décadas intentando encontrar y diseñar componentes adecuados para hacer a los vehículos híbridos competitivos con los automóviles de gasolina. Por el momento, los automóviles híbridos funcionan gracias a las denominadas pilas de combustible o fuel cells.

\section{¿Qué SON LAS PILAS DE COMBustible?}

Los principios básicos de la pila de combustible fueron descubiertos por el físico suizo Schoenbein en 1938. Grove, en 1845, desarrolló los primeros prototipos de la pila de combustible (a la cual llamaba batería de gas). En 1959 el físico británico Bacon construyó la primera célula estacionaria con éxito. 120 años después de su descubrimiento, la NASA empleó la primera pila de combustible en la misión del Géminis V. Desde entonces ha venido utilizando la pila de combustible en sus misiones, pero cada vez mejoradas.

¿Cómo funciona una pila de combustible?: La pila consta de dos electrodos, un ánodo, negativo, y un cátodo. El hidrógeno fluye hacia el ánodo donde un catalizador como el platino facilita su conversión en electrones y protones $\left(\mathrm{H}^{+}\right)$. Estos atraviesan la membrana electrolítica para combinarse con el oxígeno y los electrones en el lado del cátodo (una reacción catalizada también por el platino). Los electrones, que no pueden atravesar la membrana de electrolito, fluyen del ánodo al cátodo a través de un circuito externo y alimentan nuestros dispositivos eléctricos. La figura muestra una sola celda electroquímica que produce aproximadamente un voltio. Para aplicaciones de potencia se apilan muchas de estas celdas para formar la pila de combustible, cuyo voltaje aumenta en proporción al número de celdas apiladas (Gómez Romero 2002: 66).

Existen varios tipos de pilas de combustible, las cuales aplican diferentes técnicas en función del nivel de temperatura y aplicación:

\section{Baja temperatura}

Membrana de Polímero Sólido/Proton Exchange Membrane (PEM). Es la más adecuada para su aplicación en automoción, por presentar un buen ratio potencia/volumen, elasticidad y rápido arranque. Los inconvenientes: necesitan catalizadores caros y son muy sensibles a las impurezas.

Alcalinas (AFC). Utilizan como electrolito el hidróxido de potasio y alcanzan una eficiencia próxima al $70 \%$. La NASA utiliza estas pilas en sus cohetes y transbordadores. Su alto coste no permite su comercialización. Los inconvenientes: la eliminación del $\mathrm{CO}_{2}$ del fuel y el aire que resulta excesivamente costoso. 
Metanol Directo (DM). Empleadas en electrónica, tiene la ventaja de utilizar combustible líquido: el metanol. Su principal inconveniente está en el bajo rendimiento y su baja vida útil.

\section{Temperatura media}

Ácido fosfórico. Son las pilas más extendidas y con mayor comercialización Su eficiencia está por encima del 40\%, llegando al $80 \%$ cuando se aprovecha el calor subyacente. Utilizadas en plantas eléctricas estacionarias de hospitales, aeropuertos y otros centros de emergencia. Su inconveniente, el alto coste de su catalizador, el platino.

\section{Temperatura alta}

Carbonato Fundido (MC). Este tipo de pila consume combustibles basados en hidrocarburos. Presentan muy buena relación consumo/potencia, haciéndola una buena candidata. Tiene como desventaja la alta facilidad de corrosión y el uso de alta tecnología. Óxido Sólido (SO). Sustituye el electrolito por un material cerámico, favoreciendo su funcionamiento a alta temperatura, y de esta manera lograr una eficiencia inicial del $60 \%$. Su inconveniente está en la alta tecnología que requiere.

En el cuadro siguiente se expone la relación entre las pilas de combustible y sus condiciones para el transporte.

\section{Cuadro 1.}

Pilas de combustible y su relación con el transporte.

\section{Hydrogen Fuel Cell}

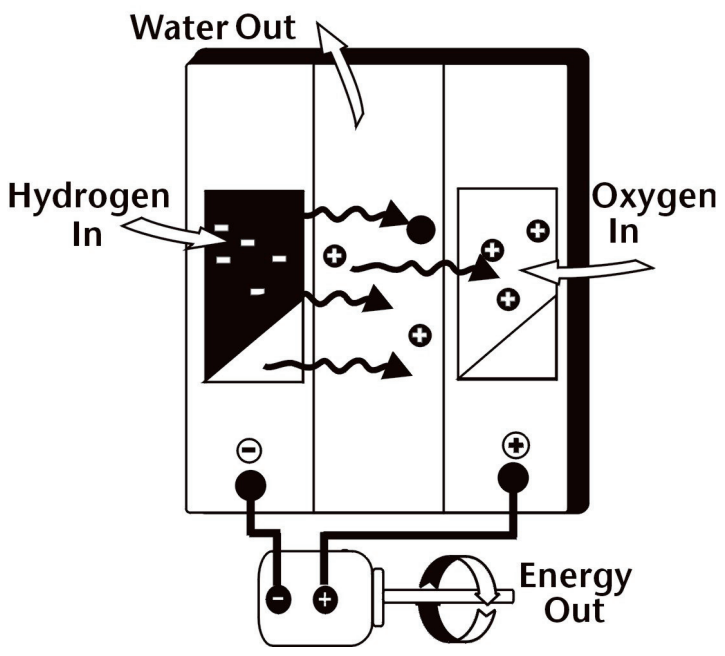

Fuente:www.scienceprep.org/images/Fuelcell.jpg 


\section{Posiciones ENCONTRAdAS SOBRE EL FUTURO ORO DE LA ENERGía: LA ECONOMÍA DEL HIDRóGENO}

Como en multitud de ocasiones, cuando algo aflora impregnando el avance o la sostenibilidad aparecen defensores y detractores. En el caso del hidrógeno con mucha más razón, puesto que puede erigirse como el nuevo valor energético, y para otros como Rifkin la solución a los problemas del mundo y especialmente en los países más desfavorecidos.

El hidrógeno ha despertado muchas pasiones y esperanzas, a las cuales bastantes científicos las consideran infundadas e incluso peligrosas. Mientras unos mantienen las grandes posibilidades del hidrógeno como generador de energía social frente al petróleo, otros ven en el hidrógeno un gran vector de energía - pero no para convertirse en el oro energético del siglo XXI- abogando por desarrollar otras energías con mayores posibilidades. Aquí exponemos dos criterios encontrados y que sirven a modo de análisis de los impactos ante la puesta en escena de la economía del hidrógeno en la sociedad.

Lovins, investigador del Rocky Mountain Institute atribuye al hidrógeno casi el calificativo del nuevo dorado energético. Mientras, Bossel, ingeniero de la European Fuel Cell Forum no niega lo positivo del hidrógeno en materia energética, pero por una serie de desventajas y dificultades no lo vislumbra como la energía del futuro.

Lovins (2005) denuncia veinte mitos generados en torno a las imposibilidades del hidrógeno como generador de energía. Los más dañinos son especialmente cuatro, y su divulgación está siendo enormemente destructiva y evita que en un futuro la población pueda beneficiarse de ella.

Mito 1. El hidrógeno es un gas demasiado inestable.

El gas de hidrógeno puede quemarse, desde luego, y se inflama con mayor facilidad que el gas natural. Pero el hidrógeno presenta una serie de propiedades físicas que lo hacen una opción más segura que los combustibles de fósiles. En primer lugar, el hidrógeno es sumamente volátil -casi 15 veces más ligero que el aire- dispersándose y mezclándose con el aire más rápidamente que los vapores de gasolina. Una vez combinado con el aire, su tendencia cuando salta una chispa es quemarse, a diferencia de los hidrocarburos cuya tendencia es a explotar con extremada potencia. La llama del hidrógeno es limpia y emite menos humo que los combustibles procedentes de hidrocarburos.

Por otro lado, ante una fuga, el hidrógeno tiende a acumularse en el techo del edificio o de la instalación de almacenamiento, disminuyendo la posibilidad de que las personas se quemen. No aconteciendo lo mismo con la gasolina y el propano por su tendencia a expandirse a los largo del edificio o de la instalación de almacenamiento.

Mito 2: El combustible de hidrógeno es demasiado caro para competir con la gasolina.

En términos de rentabilidad, el hidrógeno es más barato que la gasolina. Un coche de motor de combustión rinde energéticamente un 15\% del volumen del tanque de combus- 
tible, un híbrido como el Toyota Prius un 26\% y un coche con célula de combustible entre un $50 \%$ y $70 \%$. Por lo tanto, aunque aparentemente es más caro en términos absolutos es mucho más barato. Haciendo caso a los datos del Ministerio de Energía de USA, un kilo de hidrógeno cuesta 0,71 dólares frente a los 0,72 dólares de 5 litros de gasolina. No hacer caso de esto implica distorsionar la realidad.

Mito 3: La instalación de infraestructura del hidrógeno sería prohibitivamente cara.

Para Lovins la relación infraestructura/automóvil es la pescadilla que se muerde la cola. Si no existen vehículos que demanden hidrógeno no hay infraestructura, y si no hay infraestructura no hay demanda de automóviles con célula de hidrógeno. Con este planteamiento no será posible desarrollar el hidrógeno como combustible.

Como primera medida Lovins aboga por seguir con la infraestructura del gas natural. Esto serviría de inicio hacia la creación de demanda e implica no tener que emprender una nueva infraestructura. A medida que crezca la demanda y se vaya desarrollando la economía del hidrógeno se estará en condiciones de dotar de nuevas estructuras.

A su juicio no es necesario ir tan rápido y debemos movernos hacia la energía del hidrógeno por medio de las energías renovables. Es preciso caminar despacio y seguro. Por el momento hemos de conformarnos y desarrollar la economía del hidrógeno desde el gas natural, el metano y el etano. Insistir en que el hidrógeno se obtenga exclusivamente por medios renovables implica hacer un flaco favor al desarrollo energético, porque se despotencia al hidrógeno fomentando su negatividad.

En términos generales es necesario convencer a las personas de la importancia y beneficios del combustible de hidrógeno con la mirada puesta en generar demanda y hacerlo rentable. Tras la potenciación del hidrógeno como combustible (y más tarde como generador de energía a mayor escala) entonces nos hallaremos en las condiciones de emprender el camino a la instauración del hidrógeno puro como energía social básica. Por ello se necesita continuar investigando sobre nuevas formas de obtención de hidrógeno como la electrolisis generada por energía eólica, el metano reformado, la biomasa, etc.

Mito 4: Una economía basada en el hidrógeno podría tener un impacto imprevisto en el clima.

Es evidente el calentamiento global del planeta. La temperatura ha crecido un grado centígrado en el siglo pasado. La quema de combustibles fósiles está documentada como factor importante en el efecto invernadero. Nuestra responsabilidad reside en encontrar alternativas energéticas a los combustibles fósiles. El efecto invernadero afecta a todo el planeta: agricultura, ganadería, fauna, flora, etc.

No se sabe con exactitud si el hidrógeno como combustible afectará o no al cambio climático. A priori no tiene por qué, pues no tiene en su molécula carbono ni en el proceso de división por medio de la electrolisis interviene el carbono. Sólo en el caso de la obtención de hidrógeno por medio del gas natural en donde sí interviene el carbono. A 
tenor de ello, y con la juventud de este modelo, es obligado seguir estudiando en profundidad posibles efectos en la atmósfera del uso de estos carburantes.

Bossel no recibe la vida social del hidrógeno en los mismos términos. El tratamiento social e investigador conferido al hidrógeno lo interpreta como un derroche humano y económico. Entiende que conociendo las limitaciones del hidrógeno para transformarse en un carburante generalista social, se deberían emplear los esfuerzos en el análisis y el estudio de las fuentes energéticas existentes y de otras nuevas. El hidrógeno es un gas muy inestable, hasta tal punto que es muy inflamable y presenta alta detonabilidad. Pero también, es un gas agradecido que concede excelentes condiciones de seguridad en su tratamiento, siendo poco más de un $1 \%$ el total de accidentes producidos por el hidrógeno.

En su estudio, Bossel analiza una variedad de métodos para la síntesis, almacenamiento y distribución de hidrógeno, ya que ningún método aún ha demostrado ser superior. Para empezar, el hidrógeno no se encuentra en estado natural, se necesita sintetizarlo. En última instancia, el hidrógeno tiene que ser obtenido del agua por electrólisis a partir de fuentes renovables, y posteriormente transformarse en electricidad por medio de las pilas de combustible. La separación de hidrógeno del agua por electrólisis requiere grandes cantidades de energía eléctrica y abundante agua (Bossel 2006).

El hidrógeno no es una fuente de energía, sólo es un portador de energía. El transporte de hidrógeno, bien sea por camión o tubería presenta unos costes energéticos bastante superiores a lo establecido por la energía del gas natural o gasolina. Incluso la forma más eficiente de producción de energía por hidrógeno, las pilas de combustible, no pueden recuperar los valores perdidos de energía.

Almacenar hidrógeno líquido implica permitir que se evapore por razones de seguridad parte del gas. Así que tras dos semanas, un coche perdería la mitad de su combustible, incluso cuando no está en movimiento. "Argumenta que donde se necesitan cuatro plantas de energías renovables para alimentar una sola planta de hidrógeno puro, necesario para las pilas de combustible", y continua: "se necesitan tres de estas plantas de generación de energía para cubrir las pérdidas parasitarias de la economía del hidrógeno, mientras que sólo una de ellas es para producir energía útil" (Bossel 2006).

Para concluir, uniste en que una economía del hidrógeno es un despilfarro económico y humano. La gran cantidad de energía necesaria para aislar hidrógeno a partir de compuestos naturales (agua, gas natural, biomasa) ya sea para almacenarlos vía gas por compresión o licuefacción, y su posterior transferencia de energía al usuario, se pierde mucha cantidad de energía hasta convertirla con las pilas de combustible en electricidad útil. Solamente un $25 \%$ termina siendo efectiva. Esto es un valor inaceptable si se desea ejecutar en un futuro una economía energética sostenible. Sólo el nicho de aplicaciones como los submarinos y las naves espaciales podrían utilizar el hidrógeno como energía. Por mucho que la ciencia y la tecnología se impliquen en esta tarea, hay una cuestión con la cual no podrá luchar la economía del hidrógeno, la segunda ley de la termodinámica. Concluye proponiendo la economía del electrón, pues a su juicio tiene mayores proyecciones y puede ser un nuevo campo a abonar en material energética. 
Ambos planteamientos son defendibles. No obstante es necesario tener en consideración una cuestión fundamental, para valorar objetivamente cada una en su contexto. Los costos medioambientales y los beneficios de poner en escena una economía del hidrógeno dependen de si recurrimos al hidrógeno limpio 0 al hidrógeno sucio. El hidrógeno sucio es el procedente de los combustibles fósiles con baja eficacia y contribuyendo a una amenaza global, así como asociado a la generación de problemas medioambientales locales por la extracción y distribución de combustibles fósiles. Y el hidrógeno limpio producido por energías renovables con gran eficacia y bajo impacto medioambiental. Este sólo asegura los beneficios medioambientales que son muy importantes (Andrew 2005: 25). Lo que se baraja son dos cuestiones fundamentales, reducir las emisiones de $\mathrm{CO}_{2} \mathrm{O}$ eliminarlas. Si la intención es reducir las emisiones de $\mathrm{CO}_{2}$, la tesis de Lovins es vấlida, ahora si la pretensión alberga eliminar la pendencia social de los combustibles fósiles, tendrán que implementarse otras alternativas. Como expone Bossel, hoy por hoy -y no cree que en un futuro pueda ser- resulta difícil que el hidrógeno se transforme en el dorado de la energía social.

\section{IMPACTOS SOCIALES DE LA ECONOMÍA DEL HIDRÓGENO}

Cuando nos referimos a impactos sociales producidos por algo, conviene delimitar aquello que se va a evaluar, para posteriormente proceder al análisis de los hechos. Este requiere una valoración del ciclo de vida y su repercusión tecnológica, entrando a formar parte una serie de elementos como el impacto económico, el medioambiental, social, salud, riesgo, necesidades humanas, sensibilidad, desarrollos objetivos de la sociedad y los impactos políticos y toma de decisiones.

Por lo tanto, tomando estas cuestiones como horizonte y destacando que la implantación de tecnología nunca puede hacer que los riesgos superen descompasadamente los posibles beneficios sociales, así como tampoco que sobre los ciudadanos recaiga todo el peso de su implantación, y mermando su calidad de vida en lugar de obtener los beneficios declarados de las tecnologías. Reflexionaremos sobre los efectos de la economía del hidrógeno.

Dependiendo de cuál sea la fuente de obtención del hidrógeno varía sustancialmente el precio. Ante este hecho debemos plantearnos dos cuestiones: Si de lo que se trata es eliminar la dependencia energética de los combustibles fósiles, o reducir la emisión de $\mathrm{CO}_{2}$ a la atmósfera. Según la elección, las repercusiones sobre el impacto social varían sustancialmente. Si la intención es reducir las emisiones de gases con efecto invernadero como se ha expresado en epígrafes anteriores, el actual método de obtención de hidrógeno vía gas natural es el más rentable. Empresas, universidades y centros de investigación continúan explorando diferentes componentes para abaratar los costes, 
hacerlo competitivo y logar una menor emisión de $\mathrm{CO}_{2}{ }^{2}$. Los autobuses municipales de hidrógeno de Madrid, Barcelona y otras ciudades españolas y europeas utilizan este combustible.

Otra manera de adquirir hidrógeno es por medio de la biomasa. El aprovechamiento energético de la biomasa es la gasificación, que permite obtener gas de síntesis ( $\mathrm{CO}+$ $\mathrm{H}_{2}$ ). El gas de sintesis obtenido puede utilizarse como combustible directo, bien como fuente de $\mathrm{H}_{2} \mathrm{O}$ como materia prima química para preparar otros combustibles. La obtención de hidrógeno por gasificación de biomasa se presenta como una opción interesante, presenta la ventaja sobre el procedimiento clásico (reformado de metano con vapor de agua) de emplear un residuo y no materia prima química. Surge como una esperanza al consumo de energía, aunque emite $\mathrm{CO}_{2}$ se reduce la dependencia de los carburantes fósiles. Tiene una desventaja importante, su efecto corrosivo, reduciendo considerablemente la vida de las pilas de combustible y tuberías de transporte.

Por otra parte, si lo buscado es eliminar la dependencia de los combustibles fósiles y no emitir $\mathrm{CO}_{2}$ el proceso es bien distinto. Para logar hidrógeno libre de carbono el medio más común es el agua, y su tratamiento es la electrolisis. Este método requiere mucha energía para romper la molécula de agua y dividirla en hidrógeno y oxígeno. El suministro de energía bien sea por medio de energías renovables o nuclear, es mayor a la energía que posterior se aprovechara con el hidrógeno. Por ejemplo, el kilogramo de hidrógeno producido por medio del gas natural viene a costar unos 2 euros, donde el $45 \%$ de su producción se debe al coste del gas natural. Según el precio actual de la energía eléctrica, el $\mathrm{kg}$ de hidrógeno producido por electrolisis costaría unos 5 euros, donde el $85 \%$ del coste es producto del precio de la energía. Por otras vías, dependiendo de un amplio elenco de factores, una estimación groso modo rondaría entre 3,5 euros por kg hasta 8 euros por $\mathrm{kg}$ de hidrógeno. A esto se deben añadir costes de transporte, comercialización, etc. Este asunto es importante tenerlo de referencia cuando se están analizando las repercusiones económicas de un producto y comparándolo con otro. De esta manera se aprecia las diferencia de coste y su repercusión económica en una sociedad.

Realizar un balance de la producción del hidrógeno no atiende exclusivamente a valores finales de consumo y coste dinerario, también intervienen y de forma importante, los recursos necesarios para su producción. En este caso, las toneladas de agua necesarias para producir fuel de hidrógeno. Sólo en los Estados Unidos se estimaba en 2006 (Norskov y Christensen 2006: 1322-1323) que se necesitan cerca de 150 millones de toneladas de agua al año para cubrir las necesidades del transporte, si a esto se añade

\footnotetext{
${ }^{2}$ En Julio de 2008, investigadores de la Politécnica de Cataluña (UPC) y del CSIC idearon un catalizador que transforma el etanol en hidrógeno, y que puede ser la solución para la fabricación de coches impulsados por hidrógeno. La temperatura de funcionamiento del catalizador es de 310 grados, lo que permite que una mezcla de etanol y agua, en forma de gas, pase por sus canales interiores y salga en forma de hidrógeno y $\mathrm{CO}_{2}$, reduciendo considerablemente el $\mathrm{CO}_{2}$ frente a otros. El carburante de hidrógeno no es puro, ya que contiene carbono.
} 
la demanda de los edificios, empresas y uso doméstico, el consumo se dispara a los 500 millones de toneladas al año en EEUU. ¿La sociedad y los recursos hídricos y energéticos están preparadas para hacer frente a este reto, a la economía del hidrógeno?

Las fuel cells o pilas de carburante son el artilugio necesario para transformar por medio de energía química una sustancia en energía eléctrica y hacer que funcione un motor de combustión externa. Actualmente, como se ha enumerado sucintamente en epígrafes anteriores, existen diferentes tipos de pilas de combustible, adecuadas a demandas y necesidades diversas. Siendo la pila de combustible alcalina (AFC) la que presenta un mejor rendimiento. La NASA emplea este tipo de pila de combustible en sus actividades espaciales, pero presenta un problema importante, su alto precio. ¿Por qué este encarecimiento? Básicamente por sus componentes, los catalizadores utilizados son de platino/rutenio, los electrodos contienen gran cantidad de metales nobles, por ejemplo, el ánodo puede confeccionarse con platino y paladio, y el cátodo con oro y platino, si esto se desarrolla en todo el mundo, su abaratamiento resultará imposible, porque la demanda de oro, platino, paladio y rutenio se disparará, incrementando el valor de estos metales por la escasez y necesidad de su uso. En el caso de llegar a comercializarse, sería cuestión de plantearselo, porque si el petróleo se agota, los metales nobles también. Y sobre estos existe un mayor desconocimiento de su durabilidad. En un futuro inmediato tampoco se divisa un descenso de precios, en el mundo existen millones de millones de coches y su producción va en aumento.

En un intento de poder hacer viable los vehículos movidos por hidrógeno, las compañías de automoción han desarrollado una pila con tecnología PEM (Protón Exchange Membrane) abaratando bastante el producto. El problema no se ha solucionado del todo, porque el catalizador sigue siendo el platino. Volviendo al mismo asunto, y si se opta por diseñar todos los automóviles híbridos con este tipo de pilas, el platino disparará su precio, aumentando el coste de la pila de combustible. De nuevo entra en liza el cuestionamiento de la durabilidad. El platino es perecedero y estamos hablando de millones de coches y de pilas de vida útil entre 10 y 15 años en el mejor de los casos. El platino es un metal noble agotable. La pregunta a plantearse debe ser: ¿Es viable emprender la comercialización? En caso afirmativo, ¿Cuánto tiempo durará? Las compañías automovilísticas esperan poder comercializar estos vehículos en 5 ó 10 años. No nos llevemos a engaño, a mayor coste, menos prestaciones y más dificultades de repostaje. ¿La ciudadanía se decantará por este vehículo?

Almacenar gran cantidad de hidrógeno de manera segura y barata y posibilitar su utilización (por medio de células de combustible o por combustión directa) es otro de los retos de este producto. El hidrógeno puede almacenarse de diferentes maneras: Gasificado - comprimido a altas presiones-, líquido — por combinacion química o nanoestructuras de carbono- (Fakioglu, Yürüm y Veziroglu 2004: 1373-1374). Actualmente, el hidrógeno gasificado es el más utilizado, transportándose en botellas como gas a alta presión. Esta forma de almacenamiento no es la óptima si va a usarse como energía para un vehículo, debido al elevado volumen de dichas botellas. Si el interés esta en suministrar a un grupo de viviendas (como hacen actualmente los depósitos de propano) 
se necesita un silo cuyo volumen será el tripe al utilizado en estos momentos por las cisternas de almacenamiento de propano. Esto es muy sencillo de observar, sólo hay que fijarse en el tanque principal (donde esta el hidrógeno líquido) del transbordador espacial, cuyo volumen es mayor que la propia aeronave ${ }^{3}$. Los depósitos de hidrógeno gasificado deben ser elaborados con materiales especiales que preserven la seguridad y eviten el riesgo (Kreith y West 2004). El hidrógeno mediante composición química conlleva recurrir a numerosos metales de transición, y sus aleaciones para almacenar hidrógeno en forma de hidruros metálicos. Este proceso presenta un importante problema, el elevado peso del sistema de almacenamiento como consecuencia de los bajos niveles de retención de hidrógeno que se consiguen (Conte et al. 2004: 6). Por último las nanoestructuras de carbono, implica introducirlo en el interior de un material sólido a una temperatura y presión determinadas para posteriormente extraerlo con otros valores de presión y temperatura. Esta forma de almacenamiento permite acumular una mayor cantidad de hidrógeno en volúmenes de dimensiones a los antedichos. No es el modelo más óptimo, aunque una investigación reciente ha puesto una brizna de esperanza a las nanopartículas como sistema de almacenaje de hidrógeno (Aguey y Ares 2008).

El hidrógeno líquido y el hidrógeno gas a presión son los más extendidos en el almacenaje y transporte de hidrógeno. En el caso del hidrógeno gas a presión para su transporte, algunos sugieren utilizar la red de tuberías del gas natural. Esto no es posible porque el gas natural todavía se seguirá usando por muchos años. En el supuesto de poder hacerlo por las mismas tuberías del gas natural, éstas no servirían pues la fragilidad del acero frente al hidrógeno hace que las tuberías requieran un aislamiento especial, con fibra de carbono por ejemplo. Por lo tanto, implica un alto coste. La otra opción consiste en someter al hidrógeno a altas presiones y almacenarlo. Para trasportar hidrógeno líquido es necesario exponer al hidrógeno a una temperatura de -252 grados centígrados es decir, fuel criogénico. En Estados Unidos, la NASA y empresas que trabajan con hidrógeno líquido lo transportan en cisternas criogénicas bien sobre camión, vagón de ferrocarril o barcaza especialmente preparados. Bossel y Eliasson (2003) desaconsejan esta práctica como consumo doméstico por dos razones: 1) La energía consumida por un tanque de hidrógeno a presión viene a ser una fracción importante de la energía de hidrógeno consumida del contenido. Por ejemplo para una entrega de 40 kilómetros, la energía utilizada en el recorrido de suministro equivale al $20 \%$ de la energía de hidrógeno entregada. 2) Se necesita una flota de transporte inmensa. Siendo la relación de 15 camiones de hidrógeno por un camión de gasolina de 25 toneladas. Seleccionar esta posibilidad resulta inoperante e irracional. Primero, la flota de camiones desbordaría el tráfico rodado, su aplicación conllevaría un incremento considerable de puestos de trabajo. En segundo lugar, el consumo de carburante de hidrógeno se dispararía.

${ }^{3}$ La NASA para reducir el peso y no el volumen utiliza aleacciones especiales que encarecen demasiado el producto. La aleación actual es de alumino y litio, cuyo precio aproximado del tanque de hidrógeno ronda los 6 millones de dólares. 
La seguridad es otro principio importante en la valoración del impacto de la tecnología en la sociedad. Como anunció en su día Beck (1998) estamos ante la sociedad del riesgo, esto no simboliza tomar más riesgos de los necesarios, y bastantes son consecuencia de los efectos colaterales de la tecnología. Respecto a la seguridad del hidrógeno no existe un criterio común. Unos como Braun (2003: 114) testimonian la gran seguridad del hidrógeno frente a otros combustibles fósiles, y apostilla que el número de accidentes derivados del hidrógeno en la actualidad aproximadamente son del 1\%. En cambio, otros teóricos consideran el hidrógeno mucho más peligroso que las gasolinas (Hordeski 2005: 25).

En nuestra sociedad la herencia del hidrógeno muestra cierto rechazo, porque es visto como una fuente de desgracias. El ser humano por fortuna tiene memoria histórica, lo que en muchas ocasiones le ayuda a no cometer los mismos errores, en otros sirve para recordar cuestiones pasadas transformándolas en negativas. El hidrógeno como fuel implica una reacción química sencilla donde hay una transferencia de electrones que producen corriente eléctrica. Haciendo uso de la memoria histórica recordemos el Gran Zeppelín que explotó en 1937 en Hinderburg. La deflagración fue producto de un escape de hidrógeno. Más reciente tenemos la Bomba $\mathrm{H}$, cuya prueba conocida como Ivy Mike se realizó en el atolón de bikini en el archipiélago de las Islas Marshall, o la explosión del transbordador Challenger (1986) y su desintegración en el espacio. Todas ellas son imágenes presentes en la memoria del ser humano, y como tal, sujetas a reflexión y observación. Junto a esta simbología se refuerza en su contra la peligrosidad, la alta ignición y la toxicidad. El gran intervalo de sus mezclas con aire y la velocidad de propagación de la llama favorecen una posible explosión, mientras que la difusividad y la densidad tienden a reducir su probabilidad, especialmente en espacios abiertos. En espacios cerrados, el escape de hidrógeno tiene lugar con disminución de la temperatura lo que reduce el riesgo. En otro orden, la reacción química transcurre con reducción de volumen por lo que en vez de explosión lo que ocurre es una implosión (Gutiérrez Jodra 2005: 59). Ante todo, su capacidad de destrucción es superior a cualquier otro combustible, y ante un accidente de automóvil las consecuencias alcanzaran mayores dimensiones (Jones y Thomas 2008).

Los automóviles de hidrógeno son una apuesta por el futuro, determinadas compañías (Ford, Toyota, Honda, Volkswagen, Chrysler, etc.) han desarrollado coches híbridos combinando gasolina y electricidad, reduciendo el consumo de combustible y en consecuencia las emisiones de $\mathrm{CO}_{2}$. Estos coches presentan sobremanera dos problemas: 1) al tener que introducir dos motores en su interior, aumenta la dimensión y reducen el espacio para los pasajeros o del maletero, 2) el precio de un híbrido oscila entre 12.000 y 18.000 euros más que uno de gasolina o gasoil, dependiendo del modelo y compañía automovilística.

Otra idea reside en el empleo de hidrógeno limpio, es decir, automóviles $100 \%$ de hidrógeno, cuya impacto será de otra magnitud. Al igual que acontece con los vehículos movidos por gasolina o gasoil necesitaran un almacenaje de combustible, pero en el caso del hidrógeno como el volumen es mayor se necesitara un deposito más grande y 
más pesado, adicionado al problema de los motores, condicionaran el tamaño del vehículo. Para prestaciones iguales a sus homólogos de gasolina necesitaran más potencia, traduciéndose en mayor consumo y coste. En estado líquido, la capacidad de vaporación del hidrógeno es muy alta. Un estudio de la NASA (Ios Álamos) demostró que en diez días se había evaporado el hidrógeno de el depósito de un automóvil.

La red de distribución de combustible de hidrógeno es otro de los problemas. La Ley en California (EEUU), afectada por la fiebre de lo ecológico, ha priorizado los automóviles híbridos, no cumpliéndose lo mismo en todos los Estados de la Unión (Norskov y Christensen 2006). Cuando un vehículo viaja fuera del estado de California repostará combustible porque su auto puede funcionar con gasolina o gasoil. En cambio, un vehículo $100 \%$ de hidrógeno no podrá al no disponer el país de una red de hidrogeneras.

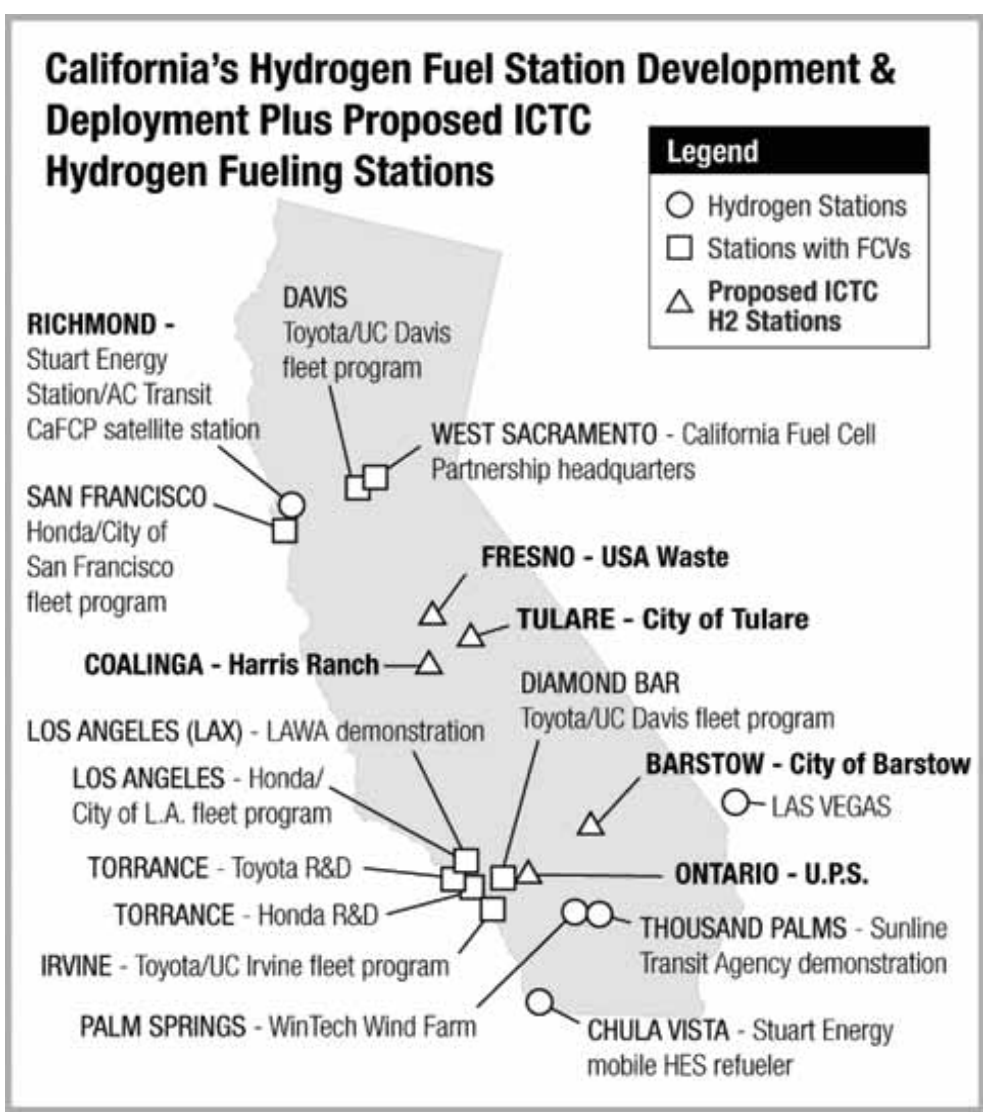

Fuente: Los Angeles Time 23 de julio de 2008. 
En el caso europeo, la incompatibilidad de infraestructuras puede ser un importante impedimento. Por dos asuntos, uno, la oferta de un solo tipo de combustible de hidrógeno, es decir, procedente de metanol o gas natural. Esto es una realidad, porque en Europa muchos automóviles consumen biodiesel, y algunos países europeos no ofertan en sus gasolineras este carburante. Esto es un problema a solucionar antes de emprender una campaña de proliferación de vehículos de hidrógeno puro. La cuestión no es baladí. Los automóviles con carburante de hidrógeno puro tienen menor autonomía y necesitarán repostar con mayor frecuencia. Esto obliga a poner hidrogeneras menos espaciadas. De Valladolid a Lisboa un automóvil movido solamente por hidrógeno deberá repostar aproximadamente entre cuatro o cinco veces, mientras uno de gasolina, dependiendo de la potencia necesitara dos. Es condición obligada estandarizar reglas internacionales en material de normas de seguridad, de equipos y de actuación con el objeto de asegurar la libre circulación de los conductores. La historia pone de relieve la tendencia a emplear mecanismos diferentes para ser diferentes. En este punto la historia deja a Europa y al mundo maltrecho, porque a la hora de unificar criterios afloran demasiado las divergencias.

El impacto medioambiental con una economía del hidrógeno sería el ideal de sostenibilidad, pero siempre y cuando se dieran las condiciones adecuadas. Y éste no es el caso. Dejar de emitir entre un $70 \%$ y $80 \%$ de $\mathrm{CO}_{2}$ a la atmósfera significaría la posibilidad de su regeneración en un espacio de tiempo relativamente pequeño, así como mejorar la calidad del aire de las ciudades, especialmente las más contaminadas como México. Incluso, con la única puesta en escena de automóviles por hidrógeno veríamos reducida la emisión de gases con efecto invernadero en un $20 \%$. Estos valores se refieren a combustible de hidrógeno con ausencia de carbono. Si su aplicación se diera en condiciones óptimas, el hidrógeno sería un vector energético de sostenibilidad.

El impacto de la toma de decisiones posiblemente sea el activador inicial más importante. En los políticos recae la capacidad de emprender imperiosamente el proyecto 0 no. Así ha sido, cuando Bush en 2003 dio un fuerte empujón al proyecto, a fecha de 2008 se va desinflando.

Una acción política de esta envergadura, en un mundo globalizado donde el petróleo es moneda de cambio, y las grandes multinacionales del crudo y países productores de petróleo están estrangulando las economías mundiales, pasaría a ser historia. La decisión no evitaría los diferentes problemas anunciados por Rifkin (2002). Algunos de ellos se agudizarían más. Rifkin declara que con la economía del hidrógeno se llegará a una justicia social, prosperidad e igualdad. Esto no será así, la economía del hidrógeno requiere un nivel tecnológico muy alto del que carecen los países más desfavorecidos y los países productores de petróleo. La formación de los ciudadanos de estos países es muy escasa. Por lo tanto, seguirán dependiendo de los países industrializados (Primer Mundo). Segundo lugar, si sus niveles productivos y tecnológicos dependen de los países del Primer Mundo, ¿Cómo van a poder producir tales materiales, aerogeneradores, plantas fotovoltaicas, electrolisis del agua, pilas de fuel, etc.? Máxime cuando algunos viven en los umbrales de la subsistencia y otros incluso por debajo. ¿Cómo se les puede prometer la energía de la libertad? 
Continuando con esta tesis, asistimos a otro de los temores de Rifkin, el problema del fundamentalismo. Su valoración está en que si se desarrolla la economía del hidrógeno, se caminará a la desaparición del fundamentalismo islámico. Todo lo contrario, se radicalizara. Los países islámicos verán mermadas sus capacidades económicas y no podrán hacer frente a la nueva energía. Sus ciudadanos achacarán de sus males a Occidente, por sus peores condiciones sociales y económicas, haciendo que surjan nuevos cofrades de la guerra santa contra el infiel.

Para finalizar, las decisiones científicas. Cuando se abre la veda de lo nuevo y con ello proyectos con suculentos fondos, algunos científicos ven la manera de sacar excelentes beneficios, aun sabiendo que dicha investigación no va a ningún sitio. Y en ocasiones cocinan el propio experimento con el objeto de seguir recibiendo fondos. Como dice Resnik (2007: 88) lo correcto, es que los científicos deben ser los primeros en salir en defensa contra los experimentos diseñados. Las normas de objetividad, la honestidad y el cuidado implican que uno debería huir de los experimentos donde se cocinan los datos. Es más, cocinar los datos deliberada e intencionalmente podría ser considerado un fraude científico, pero el fraude no es el gran problema aquí. Lo preocupante es cuando uno sucumbe a la autodecepción en la ciencia, especialmente cuando un científico se ha sometido a obtener unos resultados de la investigación con acuerdo a los intereses de quién financia la investigación.

Esto acontece en bastantes ocasiones especialmente cuando los resultados no están muy claros, o los costes son muy altos para unos rendimientos de escasa entidad. Entonces se fomentan discursos agoreros buscando implicar a un mayor número de personas evitando así desechar el proyecto. Esto no favorece en absoluto a la ciencia y tecnología, todo lo contrario, las personas han reducido su apuesta por la ciencia y tecnología ante los múltiples engaños. El impacto está ahí, desde los años 60 de la pasada centuria el descenso de estudiantes de ciencia y tecnología se ha ido reduciendo considerablemente. La ciencia y tecnología han dejado de ocupar ese lugar predominante en los individuos. Esto es preocupante y contradictorio porque estamos en una sociedad cada vez más tecnologizada y con mayor escasez de científicos y tecnólogos, causado porque los jóvenes no se decantan por estas ramas del saber.

La incursión de la economía del hidrógeno en la sociedad producirá una inusitada transformación social y energética, incluso podríamos asistir a una nueva revolución social. Su aplicación no sólo transforma el concepto de energía, también las formas de vida.

\section{¿LA SOLUCIÓN AL DÉFICIT ENERGÉTICO MUNDIAL ESTÁ EN LA ECONOMÍA DEL HIDRÓGENO?}

La economía del hidrógeno no es algo nuevo surgido de las reflexiones de un teórico social. En 1874, Julio Verne reconociendo la caducidad del carbón como fuerte energética, y percibiendo la potencialidad del hidrógeno obtenido del agua por electrolisis, pronosticó el aforismo: el agua será el carbón del futuro. Más de medio siglo después, 
Rudolf Erren ante el coste de la importación de crudo, y las emisiones contaminantes de los vehículos propuso a la Royal Society y al Gobierno Británico emplear hidrógeno producido por electrólisis del agua como combustible. En esa misma dirección dos décadas más tarde, el ingeniero británico Francis Thomas Bacon propuso utilizar el hidrógeno como sistema de almacenamiento de energía. Todos estos proyectos con casi 100 años de antigüedad no se han desarrollado. De su negativa se puede ir al discurso fácil y acusar a los lobbies del petróleo, empresas energéticas y políticos de haber hecho caso omiso en favor de sus intereses. Pero en el fondo anida la complejidad de hacer realidad tan interesante proyecto. Existen sobradas razones para no considerar la economía del hidrógeno como la energía del siglo XXI, por ejemplo:

a) La imposibilidad de poder producir tanto hidrógeno para la demanda de automóviles mundial. Ya no sólo los millones de vehículos actuales, sino los millones de automóviles ante la creciente demanda de China e India (recordemos que estos países son una de la principal causa del incremento del crudo).

b) El agua requerida para producir esa cantidad de hidrógeno. Estamos ante una sustancia problemática como es el agua. Su escasez ha llevado a la guerra a varios países. Con el tiempo se irán agudizando ante la mayor escasez de este líquido. En España hay un enfrentamiento entre comunidades autónomas por la insuficiencia de agua, esto es una mínima parte de lo necesario frente al hidrógeno como fuente energética.

c) El coste para hacer frente a la necesidad de producir hidrógeno por medio de la electrolisis. Esto no se resuelve en los mismos términos que el petróleo donde una planta puede refinar millones de toneladas de crudo. Las plantas de producción de hidrógeno presentan menos capacidad productiva, por lo que se requerirán miles.

d) El despliegue de hidrogeneras y similares para que los ciudadanos puedan repostar su depósito de combustible, independientemente de la propuesta (más mediática que real) de Rifkin (2002) de que todos los ciudadanos tengan un cargador de hidrógeno en su casa o con una cercanía inferior a 10 metros.

e) Los costes derivados en su desarrollo, producción, almacenamiento, redes de distribución, modificación de los productos y enseres de la vida cotidiana, (adaptación de las viviendas al suministro de hidrógeno, vitrocerámicas, lavadoras, etc.).

Hoy en día, la mayor parte del hidrógeno se produce a partir del gas natural por medio de reformado de vapor de metano, y aunque esto puede entenderse como una primera incursión en la economía del hidrógeno, representa tan sólo una modesta reducción en las emisiones de los automóviles procedente de los vehículos híbridos. Junto a este modelo también se puede recurrir a la electrólisis del agua, energía térmica, eólica, geo- 
térmica, solar y la transformación de biomasa (utilizando una variedad de tecnologías que van del reformado a la fermentación).

Las técnicas de procesamiento de biomasa pueden beneficiar en gran medida de la riqueza de la investigación llevada a cabo durante años en el refinado y conversión de combustibles de fósiles líquidos y gaseosos. La biomasa puede ser fácilmente convertida en combustibles líquidos, incluyendo metanol, etanol, biodiesel, y la pirolisis petróleo, que pueden ser transportados con facilidad y generar hidrógeno en el lugar. Aunque la biomasa es claramente (y necesariamente) sostenible, no puede transformarse en el suministro de hidrógeno atendiendo a las cantidades requeridas para el suministro de hidrógeno mundial. Fundamentalmente, por la limitación de los alimentos como se ha podido observar con el bioetanol disparando los precios de los cereales. Pero aun así, aunque se pueda pagar ese dinero, dejaría a la población más desfavorecida sin alimentos. Por otro lado, se sigue emitiendo $\mathrm{CO}_{2}$ a la atmósfera, en menor cantidad. Es evidente que no son sostenibles.

La única opción de sostenibilidad de producción de hidrógeno como energía es recurrir a las energías renovables, y éstas serán insuficientes para poder hacer frente a la demanda energética mundial. Y no se puede construir un mapa energético a golpe de impulsos, es necesario confeccionar el futuro mapa energético sobre una base coherente y sostenible.

Otra asunto es ampliar la diversidad de suministro energético generada por la economía del hidrógeno. El cual será bastante beneficioso para la seguridad y la estabilidad económica, pero no necesario para el medio ambiente. En función de esto, el hidrógeno como un portador de energía tiene puntos débiles relacionados, y por ello, no podrá constituirse en único valor energético (Andrews 2005: 24).

El caso de Islandia, es un ejemplo actualmente recurrente a modo de defensa de la sostenibilidad del hidrógeno como transmisor de energía. Es evidente que se ha vendido como el país que abandona la dependencia del petróleo. Vayamos por parte, Islandia es una isla pequeña y resulta fácil generar una red de hidrogeneras. Los vehículos sólo funcionarán en la isla y no tendrán problemas de traslado a otro país porque es una red cerrada de circulación. Su población es algo más de 300.000 habitantes, y no todos tienen vehículos. El país cuenta con grandes fuentes de energía como la geotérmica e hidroeléctrica que facilitan poner en escena la economía del hidrógeno por medio de la electrolisis abaratando bastante los costes. Islandia necesita importar el $100 \%$ del crudo, entre unas cosas y otras, la obtención de hidrógeno y el refinado de crudo en gasolinas viene a tener un coste similar. Su situación energética y tamaño poblacional facilitan considerablemente emprender esta transformación.

No obstante, su abandono a la dependencia del petróleo no es del todo cierto. Su deserción del petróleo atiende al consumo doméstico pero no al comercial. Porque de momento, la mayor flota pesquera del mundo seguirá moviéndose a través de combustibles fósiles, ya que, el carburante de hidrógeno tiene una escasa autonomía y requiere dotar a los barcos, si desean mantener desarrollando la actividad al igual que acontece con el gasoil, de mayor tamaño para introducir los tanques de hidrógeno. Es cierto que 
Islandia ha dado el primer paso, pero no el definitivo. Este caso concreto por sus condiciones no sirve como proyecto piloto para un posterior traslado a todo el planeta. Su propuesta será una opción de estudio de donde posiblemente saldrán importantes medidas de futuro, pero no será el proyecto generalista y salvador de la energía mundial.

El hidrógeno no podrá ser la energía sustitutiva de los carburantes fósiles por la cantidad ingente de inconvenientes e imposibilidades que lo hacen poco viable. La economía del hidrógeno ha sido de nuevo una falsa alarma, ante la necesidad del mundo de hacer frente a los problemas energéticos habidos en el planeta. Esto puede ser otro caso como el de la fusión fría. Donde se habían puesto muchísimas esperanzas, no producía impacto ambiental, los residuos nucleares no resultaban peligrosos y generaba grandes cantidades de energía. En 1989 los científicos Pons y Fleischman anunciaron haber logrado la producción de fusión fría con la correspondiente liberación de energía. Todo fue un engaño. ¿Por qué? Sencillamente cuando en los años 70 del pasado siglo se abrió la puerta a la investigación sobre la fusión fría, científicos, políticos, empresas, etc. se agarraron a ella, como la solución energética y comenzaron a reclamar investigaciones, fondos y material para abordar el asunto. Tras años de inversiones de tiempo, recursos humanos y dinero no había resultados. Para evitar el abandono al proyecto, estos investigadores se inventaron dicho fraude. Las esperanzas de la fusión fría se enfriaron. Aun existen investigaciones pero sin el entusiasmo y expectativas de antaño. Lo mismo acontecerá con la economía del hidrógeno, no será un engaño pero si humo que veremos desvanecer.

En el fondo de esta cuestión, existe otra realidad: los intereses políticos y comerciales, y no olvidemos la política y la economía, y es que la importancia potencial de hidrógeno como portador de energía puede parecer exagerada, sin embargo muy significativa. El valor energético del hidrógeno como sustituto del petróleo es el principal objetivo de las políticas de los países de la OCDE, pasando a ocupar un interés secundario las ventajas medioambientales (Andrews 2005: 24). En el momento de inexistencia de rentabilidad económica, el proyecto sufrirá un abandono, aunque su contaminación sea $0 \%$. Las posibilidades de continuar en la carretera se van estrechando, y en breve puede pasar a la cuerda floja.

\section{A mOdo de Conclusión}

La energía y su futuro es actualmente la mayor preocupación en las sociedades occidentales. El creciente desarrollo económico habido en el mundo - especialmente el de la India, China y Brasil- como consecuencia de la globalización ha traído consigo un incremento del consumo de energía, que con los mimbres actuales no se podrá hacer frente en los próximos anos. Los efectos directos han sido un progresivo ascenso en los precios de la energía y un aumento en las emisiones de $\mathrm{CO}_{2}$. Ante esta realidad, existe un consenso sobre la necesidad de elaborar un nuevo mapa energético donde las 
energías renovables ocupen el lugar dominante: solar, eólica, biomasa, etc., hidrógeno e incluso energía nuclear, para poder hacer frente a la demanda y garantizar el suministro energético a un valor adecuado, y cuidando el medio ambiente.

Con esto de fondo, las diferentes administraciones de los países de la OCDE han empezado un viaje a nunca jamás. Es evidente que no se puede negar el potencial del hidrógeno, pero debemos ser realistas, el hidrógeno según las leyes de la física y la química no podrá ser el trasmisor universal de energía a un precio razonable y en los mismos términos que sus competidores. Esto no significa abandonar su estudio e investigación, sino proceder como una energía renovable más.

Es necesario seguir una línea ascendente de investigación y desarrollar nuevas alternativas a los combustibles fósiles, pero es cierto que deben y tienen que hacerse sobre una base sólida, y no bajo bonitas misivas escasas de realidad y fundamento científico.

El crudo se agota en nuestro planeta y es necesario encontrar alternativas energéticas al petróleo. No podemos pensar en el hidrógeno y otras energías alternativas como el pan de los pobres, porque seguirán los mismos controlando la energía. Y ese deseo de Rifkin de hacer libres e iguales a todo el mundo, se quedará indudablemente en un deseo y no en una realidad.

El cambio climático está ahí, no es una invención ni una fantasía sino una realidad que lleva muchos años cambiando y trasformando el ambiente del planeta. Por lo tanto, todo esfuerzo en mejorar el medio ambiente no será en vano, pero tampoco escudarse en ello para alcanzar objetivos particulares y personalistas en lugar de metas globales. El hidrógeno es una energía renovable más, y como tal será otro apoyo para competir nuestro puzle energético y solventar las carencias habidas por el crecimiento económico y la demanda mundial. Los esfuerzos económicos y humanos se deben destinar a todos los potenciales: energético, geotérmica, eólica, mareomotriz, biomasa, fotovoltaica, etc., en la suma esta la razón y no en sus partes. No estamos descubriendo nada nuevo, los alquimistas propusieron el hidrógeno como energía, lo propio con la energía solar, y con la mareomotriz otro tanto de lo mismo, que data de 1799. Por lo tanto, estamos en la obligación de mejorar estas propuestas con la alta tecnología que poseemos. Tampoco cerremos puertas a ninguna fuente de energía, atendiendo a los criterios de lo políticamente correcto, porque la energía nuclear de fusión, si puede ser el "dorado" energético. La ilusión, al igual que la economía del hidrógeno, desempeña una importante función psicológica en nuestra sociedad, y muchos en la comunidad técnica lo manipula. Los ingenieros y científicos deben jugar un papel importante en la sociedad, educar al público y a los políticos sobre las verdaderas opciones. Debemos recordar una vieja caricatura en la serie de Pogo titulada "hemos encontrado al enemigo y está entre nosotros" (Shinnar 2005: 480). 


\section{REFERENCIAS BibLIOgRÁfICAS}

Aguey Zinsou, K. F. y J. R Ares Fernández. 2008. "Synthesis of Colloidal Magnesium: A Near Room Temperature Store for Hydrogen." Chemistry of Materials 20: 376-378.

Ashley, S. 2005. "On the road to Fuel Cell cars." Scientific American 292: 52-55.

Andrews, C. J. 2005. "Energy Security as a Rationale for Governmental Action." IEEE Technology and Society Magazine. Summer: 16-25.

Beck, U. 1998. La sociedad del riesgo: hacia una nueva modernidad. Barcelona: Paidos.

Behar, M. 2005. "Warning: the hydrogen economy may be more distant than it appears." Popular Science 266: 65-68.

Borronibira, C. H. 2001. "Fuel Cells." Macmillan Encyclopedia of Energy, edited by Zumerchik, John. New York: Macmillan.

Bossel, U. 2006. "Does a Hydrogen Economy Make Sense?." Proceedings of the IEEE 94: 34-48.

Bossel, U. 2007. Why a hydrogen economy doesn't make sense. Consulta 18 de julio de 2008. (http:/l www.physorg.com/news85074285.html).

Braun, H. 2003. "Safety of Hydrogen" en Renewable Hydrogen Forum, edited by Middleton, P., R. Larson., M. Nicklas. y B. Collins. Washington, D. C.: American Solar Energy Society.

Cammack, R., M. Frey. and R. Robson. eds. 2001. Hydrogen as a fuel. Learning for nature. Londres: Taylor \& Francis.

Conte, M., A. lacobazzi, M. Ronchetti and R. Vellone. 2002. "Hydrogen economy for a sustainable development: state of the art and technological perspectives" Journal of Power Sources 100: 171187.

Conte, M., P. P. Prosini y S. Passerini. 2004. "Overview of energy/hydrogen storage: state of the art of the technologies and prospects for nanomaterials" Materials Science and Engienering 108: 2-8.

Cothran, H. 2003. Global resources: opposing viewpoints. San Diego: Greenhaven Press.

Dickson, E., J. Ruyan. and M. Smulyan. 1977. Hydrogen energy economy; a realist appraisal of prospects and impacts. New York: Praeger.

Dunn, S. 2001. Hydrogen futures: towards a sustainable energy system. Washington, D. C.: Worldwach Institute.

Gómez Romero, P. 2002. "Pilas de combustible: energía sin humos" Mundo científico 233: 66-71.

Gutiérrez Jodra, L. 2005. "El hidrógeno, combustible del futuro". Rev. R. Acad. Cienc. Exact. Fís. Nat. 99: 49-67. 
Fakioglu, E., V. Yürüm and T. N. Veziroglu. 2004. "A review of Hydrogen Storage Systems Based on Boson and Its Compounds." International Journal of Hydrogen Energy 29: 1371-1376.

Helgi, H. T., H. P. Ingolfssonb and T. Jenssona. 2008. "Optimizing site selection for hydrogen production in Iceland." International Journal of Hydrogen Energy 33: 3632-3643.

Hordeski, M. F. 2006. Alternative fuels: the future of hydrogen. Boca Raton: CRC.

Johansson, T. B. ed. 1993. Renewable energy: sources for fuels and electricity. Washington: Island Press.

Jones, R. H. y G. J. Thomas. 2008. Material for the hydrogen economy. Boca Raton: CRC Press.

Kasting, J. F. 2004. "When Methane Made Climate." Scientific American 291: 71-75.

Kreith, Fy R. West. 2004. "Fallacies of the hydrogen economy: A critical analysis of hydrogen production and utilization", Journal of Energy Resources Technology 126: 249-257.

Lovins, A. y H. Lovins. 2005. "A new age of resource productivity". Pp. 129-145, in Environmentalism and the technologies of tomorrow: shaping the next industrial revolution, edited by Olson, R. and D. Rejeski. Washington D. C: Island Press.

Maacka, M. H. and J. B. Skulasonb. 2006. "Implementing the hydrogen economy." Journal of Cleaner Production 14: 52-64.

National Research Council. 2004. The hydrogen economy: opportunities, costs barriers and r\&d, needs. Washington: National Academy Press.

Nazri, G. A., H. Zazri, R. Joung and P. Chen. eds. 2004. Materials and technology. Warrendale: MRS.

Nieuwenhuis, P y P. Wells. 2003. The automotive industry and the environment. Boca Raton: CRC.

Norskov, J. K and C. H. Christensen. 2006. "Toward Efficient Hydrogen Production at Surfaces." Science 312: 1131-1326.

Ogden, J. 2002. "Hydrogen: The Fuel of the future?." Physics Today 55: 69-74.

Resnik, D. 2007. The price of truth. Londres: Oxford University Press.

Rifkin, J. 2002. The hydrogen econom: the creation of the worldwide energy and the redistribution of power on earth. Nueva York: Putnam.

Romm, J. J. 2004. The Hype about hydrogen, fact and fiction in the race to save the climate. Washington: Island Press.

Russel M. 2003. "Liability and the hydrogen economy." Science 301: 47.

Shinnar, R. 2005. "The mirage of the $\mathrm{H}_{2}$ economy". Pp. 477-480 in Water Encyclopedia, vol. 4, edited by Lehr, J. y J. Keeley. New York: Wiley. 
Smith, W. N. y J. D. Santangelo. eds. 1980. Hydrogen production and marketing. Washington D. C.: American Chemical Society.

Sorensen, B. 2005. Hydrogen and fuel cells. Burlington: Elsevier Academic Press.

Sperling, D. y J. S. Cannon. 2004. The Hydrogen energy transition. Morning toward the post petroleum age in transportation. Burlington: Elsevier Academic Press.

Sperling, D. y J. Ogden. 2004. "The Hope for Hydrogen." Science and Technology 2: 82-86.

Tromp, T. K. 2003."Potential environmental impact of the hydrogen economy on the stratosphere" Science 300: 1470-1472.

Turner, J. 2004. "Sustainable Hydrogen Production." Science 305: 972-974.

JESÚS VALERO MATAS es Doctor en Sociología (UCM). Licenciado en Sociología (UCM) y Licenciado en Ciencias Políticas y de la Administración (UCM). Actualmente es profesor de sociología en la Universidad de Valladolid. Ha sido profesor visitante en diversas universidades extranjeras, Edinburgh University, Auckland University, Colorado School of Mines, UNAM, Polish Academic Nauk, etc. Tiene en su haber más de 20 publicaciones en revistas nacionales e internacionales y varios libros.

RECIBIDO: $13 / 08 / 08$

ACEPTADO: $16 / 09 / 09$

Publicado on-line: 29 de abril de 2010 